\title{
The stability of TNT, RDX and PETN in simulated post-explosion soils: Implications of sample preparation for analysis
}

\author{
Yu HA ${ }^{\mathrm{a}, \mathrm{b}, \mathrm{d}}$, DeTata DA ${ }^{\mathrm{c}}$, Lewis $\mathrm{SW}^{\mathrm{a}, \mathrm{b}^{*}}$, Nic Daeid N $\mathrm{N}^{\mathrm{d}}$ \\ a Department of Chemistry, Curtin University, GPO Box U1987, Perth, 6845, WA, Australia, \\ holly.yu@postgrad.curtin.edu.au \\ ${ }^{\mathrm{b}}$ Nanochemistry Research Institute, Curtin University, GPO Box U1987, Perth, 6845, WA, Australia \\ ${ }^{\mathrm{c}}$ Forensic Science Laboratory, ChemCentre, Manning Road, Bentley, 6102, WA, Australia \\ ${ }^{\mathrm{d}}$ Centre for Anatomy and Human Identification, School of Science and Engineering, University of Dundee, UK \\ *Corresponding Author: s.lewis@ curtin.edu.au (Simon Lewis)
}

\begin{abstract}
Explosives residues in soils may be a useful source of evidence following the detonation of an improvised explosive device (IED), such as a vehicle-borne IED. Soil samples collected from the vicinity of an explosion scene will often be stored for some time prior to analysis, yet explosives residues in soil samples are susceptible to rapid degradation or transformation. Although some research has assessed the use of different storage temperatures with a view to reducing explosives' degradation over time, further research examining the degradation of explosives in soil when stored under a variety of storage conditions is crucial to determine the optimal sample collection and storage procedures for soil containing explosives residues. In this work, three different soils were spiked with solutions of TNT, RDX and PETN and stored either at room temperature, refrigerated or frozen. Samples were extracted over 6 weeks, with additional samples gamma-irradiated or nitrogen purged prior to storage. Experimental results indicate that TNT underwent very rapid degradation at room temperature, attributed to microbial action, whereas PETN and RDX proved to be more stable. Gamma irradiation and nitrogen purging proved of some benefit for mitigating TNT degradation, with lower storage temperatures ultimately proving the most effective method of mitigating degradation.
\end{abstract}

\section{Keywords}

Forensic analysis; explosives; soil; degradation; liquid chromatography

\section{Introduction}

Explosives are a common soil contaminant at a range of sites, including military training and firing ranges and areas associated with landmine detonations [1-5]. As many explosives are toxic and can have adverse environmental effects, a large body of research has been directed towards the detection and remediation of such explosives residues in soil. Explosives bioremediation research to date can broadly be classified into two groups, the first being research involving historical field-samples of explosives-contaminated soil [2-4, 6-11], and the second being research starting with blank, explosives-free soil, with explosives spiked into the soil to assess their degradation and transformation [5, 12-32]. 
In comparison to this broad set of bioremediation research, very little research has investigated the degradation of 'newly-deposited' explosives residues from bombing incidents. As soil from the vicinity of vehicle bombings is likely to be a good source of such residues [33], this present work is concerned with investigating the degradation of 'newlydeposited' explosives following a bombing incident.

Historically, soil samples suspected of containing explosives residues have been collected and transported to a laboratory for analysis. Though recent research has been directed towards the development of at-the-scene detection techniques for explosives in soil [34-36], it is likely that for the foreseeable future, soil samples will continue to be transported back to laboratories for analysis. It would therefore be of use to assess a variety of storage conditions with the aim to maximise the stability of explosives in such soil samples, prior to their analysis.

A number of processes may affect the stability or attenuation of explosives in soil. Biodegradation of explosives by soil-borne microbes and bacteria is one of the major pathways for the attenuation of explosives in soil. RDX can biodegrade under both aerobic and anaerobic conditions [1, 37], with less known about the biodegradation of PETN [37]. TNT is highly susceptible to reduction by bacteria, and has been shown to rapidly biodegrade under both aerobic and anaerobic conditions [37]. The initial transformation products are aminodinitrotoluenes (ADNTs; either 2-ADNT or 4-ADNT), with 4-ADNT reported to form in greater quantity than 2-ADNT [14] due to steric effects [37, 38].

By storing soil samples at low temperatures, the rate of microbial degradation of any explosives may be reduced. However, although a large proportion of research investigating the degradation of explosives in soil has stored soil samples at room temperature $[5,8,9,13$, $14,19,23-25,27,28,32]$, comparatively little research $[12,18,22]$ exists in the literature where researchers have trialled different storage temperatures to assess the effect of temperature on the stability of explosives in soil samples. One recent example comes from DeTata et al. [12], who investigated the fate of a variety of explosives in 3 different soils. The majority of the soil samples were stored at room temperature, though one soil type was also spiked and stored refrigerated or frozen, with the explosives displaying a higher stability in the samples stored at lower temperatures. The authors concluded it would be useful to assess the stability of explosives under different storage conditions in a wider variety of soils.

Microbial activity in soils can be either aerobic, requiring oxygen, or anaerobic, without requiring oxygen. Almost all previous research investigating the degradation of explosives in soil has involved the storage of soil samples with an air headspace $[5,9,12,15-18,21,22$, $28,30]$, allowing aerobic microbial degradation to take place. Storage under a nitrogen headspace may have the potential to minimise the biotic degradation and transformation of explosives by preventing aerobic microbial degradation pathways.

Moshe et al. [8] investigated the effect of nitrogen purging on explosives degradation. The authors enriched soil samples containing TNT, RDX and HMX by adding molasses and a nutrient-containing solution, to form slurries. Interestingly, degradation of each of the explosives was observed despite the anaerobic conditions, suggesting that anaerobic microbial degradation of the explosives may have occurred. Although Moshe's work concerns the use of a nitrogen headspace for soil-based slurries, no reference could be found 
in the literature where much drier, unsaturated soil samples (such as those recovered from a post-explosion scene) were stored under a nitrogen headspace.

Whereas nitrogen purging soil samples is likely to only affect any aerobic microbial activity, a comprehensive sterilisation technique is likely to eliminate all aspects of microbial activity, and thus may prevent the majority of explosives degradation in post-blast soil samples. Ainsworth et al. [19] investigated the transformation of TNT and RDX in steam-sterilised soils, finding that TNT underwent abiotic transformation. Similarly, Larson et al. [28] investigated the fate of TNT and RDX in 6 soils. The authors compared sterilised and unsterilised soils, and concluded that TNT and RDX transformation occurred in both the sterilised and unsterilised soils, though the transformation levels were higher in the unsterilised soils. Later, Hawari et al. [16] investigated the fate of RDX in agricultural topsoil, comparing the rate of RDX sorption and transformation in both unsterilised and cobalt-60 sterilised soils. In the unsterilised soil, the level of RDX dropped dramatically after 2 weeks, with the RDX completely disappearing within 5 weeks. In contrast, in the sterilised soil, high recoveries of RDX were obtained even after 5 weeks. It should be noted that in each of these previous studies the soil samples were sterilised prior to the addition of explosives. No studies have investigated soil already containing explosives before sterilisation, which is representative of a real-life post-explosion situation.

In addition to microbial-based attenuation, explosives may undergo adsorption to many potential sorbents within a soil matrix, such as organic carbon, microorganisms, humic material, and surfaces present in the clay fraction of soils $[1,10,14,15,19,26,30,37,39$, 40]. TNT [39, 41] and RDX [19] have both been reported to undergo adsorption to organic carbon in soil. The interactions of explosives with clay minerals in soil have also been explored [1, 15, 25, 26, 29], with high adsorption coefficients reported between TNT and clay minerals (e.g. $K_{\mathrm{d}}=21500$ for adsorption onto Montmorillonite clay [29]), and comparatively lower coefficients between RDX and clay minerals (e.g. $K_{\mathrm{d}}=1.2$ for adsorption onto Montmorillonite clay [29]).

Explosives transformation products, particularly the amino derivatives of TNT, can also undergo irreversible covalent binding with humic acids present in soil [6, 15, 26, 42-44]. For more information on this phenomenon, reference may be made to Thorn and Kennedy [42], who illustrate 18 such possible covalent binding reactions. It is clear that the attenuation of explosives within a soil sample can be caused by a variety of factors. Therefore, when considering mechanisms for the attenuation of explosives in soils, it must be borne in mind that this is a highly complex process. It should be noted that loss due to volatilisation was not considered in this work, as it is acknowledged [37] that the vapour pressures of TNT, TNT transformation products, RDX and PETN in environmental samples are negligible.

As briefly outlined here, limited work has been performed to assess the stability of explosives in soil samples when stored at a variety of temperatures, so the present work aims to enhance current understanding of the fate of explosives when stored at various temperatures. In addition, as many explosives are susceptible to microbial degradation, storage of soil samples using a nitrogen headspace may act to reduce the rate of aerobic microbial degradation of the explosives and may thus offer an enhanced stability of the explosives over time. Similarly, although work has been performed to assess the fate of explosives spiked into sterilised soils, no research has assessed the fate of explosives deposited into soil which was sterilised after 
being spiked with explosives. This novel work will therefore enable an assessment of whether soil sterilisation is beneficial for enhancing the stability of explosives within a soil sample.

In the present work, an aqueous solution of TNT, RDX and PETN was spiked into $5 \mathrm{~g}$ portions of 3 different soils, and the samples stored in one of 5 conditions: 1) storage in the dark at room temperature, 2) refrigerated, 3) frozen, 4) nitrogen-purged then stored in the dark at room temperature, and 5) gamma-irradiated then stored in the dark at room temperature. Samples were extracted periodically over 6 weeks, and the level of each explosive quantified. These experiments will enable an assessment to be made of a variety of possible storage conditions and sample treatments for soil samples collected from the vicinity of an explosion, with the ultimate aim to minimise or prevent any explosives degradation from occurring.

\section{Materials and Methods}

\section{Solvents and chemicals}

Acetonitrile (UV grade) was Honeywell, Burdick \& Jackson Brand ${ }^{\circledR}$. 18.2 $\Omega$ Milli-Q water was obtained from a Sartorius Arium 611VF water purification system. Explosives standards were obtained from LECO Australia, Castle Hill, NSW, and included the following: PETN, $1000 \mu \mathrm{g} / \mathrm{mL}$ in methanol; 2,4,6-Trinitrotoluene, $1000 \mu \mathrm{g} / \mathrm{mL}$ in acetonitrile; RDX, 1000 $\mu \mathrm{g} / \mathrm{mL}$ in acetonitrile; 2 -amino-4,6-dinitrotoluene, $1000 \mu \mathrm{g} / \mathrm{mL}$ in acetonitrile; 4-amino-2,6dinitrotoluene, $1000 \mu \mathrm{g} / \mathrm{mL}$ in acetonitrile; 1,2-dinitrobenzene (used as an internal standard), $1000 \mu \mathrm{g} / \mathrm{mL}$ in methanol.

\section{Consumables}

$50 \mathrm{~mL}$ amber glass tall round bottles $(24 \mathrm{~mm})$ and white ringseal $24 \mathrm{~mm}$ polypropylene screwcaps were obtained from Cospak, Welshpool, WA. $5 \mathrm{~mL}$ Luer slip syringes (without needle) were Nipro Australia or Terumo brand. PTFE membrane $15 \mathrm{~mm}$ syringe filters $(0.2$ $\mu \mathrm{m})$ were Phenomenex brand. $20 \mathrm{~mL}$ clear precleaned boro I-Chem vials with septa were Thermo Fisher Scientific brand. LC vials were Agilent $2 \mathrm{~mL}$ clear screw cap vials or Phenomenex $2 \mathrm{~mL}$ clear Verex vials. Syringe needles for nitrogen purging were Terumo single use Neolus needles (21 $\mathrm{G}$ x 1.5"). Parafilm "M" Laboratory film (Bemis Flexible Packaging, Neenah, WI) was used to seal nitrogen-purged samples.

\section{Explosives spiking solution preparation}

$2 \mathrm{~mL}$ each of the neat $1000 \mu \mathrm{g} / \mathrm{mL}$ TNT, PETN and RDX standards were separately concentrated under nitrogen to a final volume of $<50 \mu \mathrm{L}$. Each explosive was then reconstituted with Milli-Q water and the aqueous solutions mixed and made up to a total volume of $200 \mathrm{~mL}$. This aqueous spiking solution used for the in-lab spiking soil degradation experiments had a residual organic solvent content of $<0.1 \%$. The solution was stored in a fridge at $1{ }^{\circ} \mathrm{C}$. Prior to each use, the solution was sonicated for $10 \mathrm{~min}$, and 3 separate samples taken from the spiking solution and analysed for their levels of TNT, RDX and PETN. An average of these three levels was then used as a reference spiking value to calculate percentage recoveries from the aged samples. 


\section{Soil preparation}

Spearwood sand was obtained from the Soil Laboratory of ChemCentre, WA. Native and landscape soils were obtained from Soils Ain't Soils, Perth, WA. The native soil was reported to contain sands, red loam and peat, and the landscape soil was reported to contain sands, fertilisers and peat. Analysis of each soil's properties was performed by the Environmental Chemistry Section at ChemCentre, with selected information on the soils' properties displayed in Table 1.

Table 1: Properties of Spearwood sand, native and landscape soils used during this work (total organic carbon levels are determined independently from sand, silt and clay, thus each row totals $>100 \%$ )

\begin{tabular}{ccccc}
\hline & $\begin{array}{c}\text { Total organic carbon } \\
(\%)\end{array}$ & $\begin{array}{c}\text { Sand } \\
(\%)\end{array}$ & $\begin{array}{c}\text { Silt } \\
(\%)\end{array}$ & $\begin{array}{c}\text { Clay } \\
(\%)\end{array}$ \\
\hline Spearwood sand & 0.95 & 95.5 & 1.5 & 3 \\
Native soil & 1.21 & 93.5 & 2.5 & 4 \\
Landscape soil & 1.76 & 92 & 3.5 & 4.5 \\
\hline
\end{tabular}

Soils were dried in an oven at $40{ }^{\circ} \mathrm{C}$ for 48 hours then passed through a $2 \mathrm{~mm}$ sieve prior to use. $5 \mathrm{~g} \mathrm{(} \pm 0.05 \mathrm{~g}$ ) soil samples were portioned into $50 \mathrm{~mL}$ amber glass vials (for the majority of samples) or clear glass $20 \mathrm{~mL}$ I-Chem vials (for the nitrogen-purged and gamma-irradiated samples).

\section{LC instrument and LC method}

Analysis was performed on an Agilent 1200 LC-UV instrument equipped with a DAD detector using ChemStation Rev. B.04.03-SP1 software. The LC column was an Agilent Zorbax Extend-C18 $5 \mu \mathrm{m} 4.6 \times 150 \mathrm{~mm}$ column. A flow rate of $1.6 \mathrm{~mL} / \mathrm{min}$ was used with a total run-time of $22 \mathrm{~min}$. The following mobile phase sequence was used: 0-11.5 $\mathrm{min}, 28: 72$ MeCN: $\mathrm{H}_{2} \mathrm{O}$; 11.5-13 min, ramp to 50:50 MeCN: $\mathrm{H}_{2} \mathrm{O}$; hold for $4 \mathrm{~min}$; 17-18.5 min, decrease to $28: 72 \mathrm{MeCN}: \mathrm{H}_{2} \mathrm{O}$; hold for $3.5 \mathrm{~min}$ until end of run, with a constant column temperature of $40{ }^{\circ} \mathrm{C}$. TNT, 2-ADNT and 4-ADNT were detected at $240 \mathrm{~nm}$, with RDX, 1,2-DNB and PETN detected at $210 \mathrm{~nm}$.

Calibration curves containing the 5 analytes of interest (TNT, PETN, RDX, 2-ADNT and 4ADNT) along with an internal standard (1,2-DNB) were prepared in 52:48 $\mathrm{MeCN}: \mathrm{H}_{2} \mathrm{O}$ to give on-column explosives levels of 5, 10, 20, 35, 50 and $100 \mathrm{ng}$ and $10 \mathrm{ng}$ 1,2-DNB, following a $10 \mu \mathrm{L}$ injection. The instrument was re-calibrated prior to sample analysis, with the resulting calibration curves producing $\mathrm{R}^{2}$ values greater than 0.998 . A typical chromatogram obtained using this LC method is provided in the Supporting Information, Figure S-1.

\section{Soil extraction study}

A mixed explosives spiking solution containing TNT, RDX, PETN, 2-ADNT and 4-ADNT each at $0.2 \mathrm{mg} / \mathrm{mL}$ was obtained by mixing equal volumes of $1 \mathrm{mg} / \mathrm{mL}$ standards of each compound. $50 \mu \mathrm{L}$ of this spiking solution ( $10 \mu \mathrm{g}$ of each analyte) was spiked onto $7 \mathrm{x} 5 \mathrm{~g}$ soil 
samples for each of the 3 soil types. After spiking, the soil samples were left to stand at room temperature (rt) for $30 \mathrm{~min}$, to allow residual spiking solvent to evaporate. $5 \mathrm{~mL} \mathrm{MeCN}$ was then added to each soil sample bottle, before loosely capping the vials and sonicating for 30 min at rt. An aliquot of the resulting soil extract from each sample was filtered through a 5 $\mathrm{mL}$ disposable syringe connected to a $0.2 \mu \mathrm{M}$ syringe filter, with the filtrate collected into a clean test tube. $500 \mu \mathrm{L}$ of this solution was transferred into an LC vial, before adding $480 \mu \mathrm{L}$ Milli-Q water and $20 \mu \mathrm{L}$ of a $0.01 \mathrm{mg} / \mathrm{mL} \mathrm{MeCN}$-based solution of the 1,2-DNB internal standard, to give an overall volume of $1000 \mu \mathrm{L}$ and a solvent composition of 52:48 $\mathrm{MeCN}$ :water. $50 \mu \mathrm{L}$ of each sample was injected in duplicate onto the $\mathrm{LC}$, and the results averaged.

In addition to this acetonitrile-based spike and soil extraction, an aqueous spike extraction was also trialled. Spearwood sand was selected as a single soil to analyse. A set of 7 x $5 \mathrm{~g}$ Spearwood soil samples were wetted with $0.25 \mathrm{~mL}$ Milli-Q water, before the addition of 1 $\mathrm{mL}$ of the aqueous spiking solution to each vial. Following this, $5 \mathrm{~mL} \mathrm{MeCN}$ was added to each vial, and the vials sonicated for $30 \mathrm{~min}$, before filtering the resulting extracts through 0.2 $\mu \mathrm{M}$ syringe filters and placing $625 \mu \mathrm{L}$ of this filtered extract into an LC vial. $355 \mu \mathrm{L}$ Milli-Q water was added, along with $20 \mu \mathrm{L}$ of $0.01 \mathrm{mg} / \mathrm{mL} 1,2-\mathrm{DNB}$ in acetonitrile, to give a final volume of $1000 \mu \mathrm{L}$. This gave the same solvent proportion (52:48 $\left.\mathrm{MeCN}: \mathrm{H}_{2} \mathrm{O}\right)$ as for the previous soil extraction samples. $50 \mu \mathrm{L}$ of each such sample was injected in duplicate onto the $\mathrm{LC}$, and the results averaged.

\section{Sample preparation: Alternate storage temperatures}

For the varied storage temperature samples, $5 \mathrm{~g}( \pm 0.05 \mathrm{~g})$ of each soil was placed into an amber vial before spiking with $0.25 \mathrm{~mL}$ tap water and leaving for 3 days to re-establish microbial growth. Following this, $1 \mathrm{~mL}$ of the aqueous spiking solution was added, and the vials placed into their respective storage environments (a sealed box at room temperature, refrigerated at $1{ }^{\circ} \mathrm{C}$ or frozen at $-20{ }^{\circ} \mathrm{C}$ ). Samples were prepared in duplicate for each time point. Following their designated ageing period, each sample was extracted following the procedure detailed above. The samples stored at room temperature acted as the 'no treatment' samples (i.e. air headspace/non-irradiated samples) against which to compare the nitrogenpurged and gamma-irradiated sample recoveries.

\section{Preparation of nitrogen-purged samples}

Following the re-establishment of microbial activity, $5 \mathrm{~g}( \pm 0.05 \mathrm{~g})$ soil samples were spiked with $1 \mathrm{~mL}$ of an aqueous explosives spiking solution, with each spike containing approximately $10 \mu \mathrm{g}$ each of TNT, RDX and PETN. Samples were prepared in duplicate for each time point. The spiking solution was sonicated prior to use, to degas the solution and remove any dissolved oxygen from the solution. After capping the vials, the headspace of each sample was purged with nitrogen. This was achieved by piercing the septum of the IChem vial lid using a fine needle connected to a nitrogen supply, and purging the sample with nitrogen for 15 minutes to ensure that all contained air within the sample had been replaced with nitrogen. An unconnected needle was inserted through the septum to ensure nitrogen flow through the sample. 
Nitrogen was applied through a Reacti-Vap Evaporating Unit (Rockford, Illinois) fitted with an Alltech Digital Flow Check HR ${ }^{\mathrm{TM}}$ flow meter, operated using DFC Low-Flo 1.01 software and measuring the nitrogen flow using Standard Cubic Centimetres per Minute (SCCM) mode. The evaporating unit contained 9 termini for syringe needles, allowing 9 vials to be purged simultaneously. The nitrogen flow rate was held at approximately $414 \mathrm{~mL} / \mathrm{min}$, to give an average flow into each of the 9 vials of $46 \mathrm{~mL} / \mathrm{min}$ (the contained atmosphere within each vial was twice fully displaced with nitrogen each minute). Nitrogen purging was performed for 15 minutes for each set of vials, flushing through with 30 volumes of nitrogen given the $23 \mathrm{~mL}$ vial volume, leaving a nitrogen headspace, see Figure S-2. Upon removal of the needles from the $1 / 8$ " thick PTFE/silicone septum, the needle holes appeared to self-seal. However, in order to fully ensure that the nitrogen gas would not diffuse out from the samples, the entire flat side of the lid (containing the septum) was covered with a taut layer of Parafilm including the area around the screw threads. Samples were stored immediately in a dark cupboard at room temperature prior to extraction and analysis at their designated time points as detailed above.

\section{Preparation of gamma-irradiated samples}

Duplicate $5 \mathrm{~g}$ soil samples were pre-wetted and spiked with aqueous spiking solutions as detailed for the nitrogen-purged samples. Samples were placed into a $2 \mathrm{~L}$ metal paint can and irradiated for 16.3 hours to give a total irradiation dose of $70 \mathrm{kGy}$. The irradiation process was initiated within 30 min of soil spiking. Gamma irradiation was performed on a MDS Nordon Gammacell 220E irradiator containing cobalt-60 rods. The irradiation dose was verified using a SteriRite Gamma/Ebeam adhesive indicator label (PMA Manufacturing, Penang, Malaysia). At the end of the irradiation time, the samples were stored in the dark at room temperature prior to extraction and analysis at their designated time points. After their designated ageing time, samples were extracted as per the 'no treatment' samples detailed above.

\section{Results and Discussion}

\section{Soil extraction study}

The majority of research focusing on the detection of explosives in soil has used EPA Method 8330 [45], capable of the extraction of a range of explosives from soil, with detection by HPLC-UV [46]. The method involves an 18 hour sonication of $2 \mathrm{~g}$ soil samples in $10 \mathrm{~mL}$ acetonitrile. More recently, an updated version of Method 8330 was proposed in the form of EPA Method 8330B [45], capable of detecting a greater number of explosives, including PETN. Both EPA Methods 8330 and 8330B were developed for the analysis of fieldcontaminated soils, such as soils exposed to explosives from military training activities [45]. A number of studies have therefore reported the use of either EPA Method 8330 or 8330B for the extraction of explosives from field-contaminated soils [2-4, 7, 14, 22, 47]. Some studies have also utilised these methods for the extraction of explosives from blank soils spiked with explosives, to resemble field-contaminated soils [15, 16, 18, 21, 23-25, 30, 31]. 
Recently, DeTata et al. [12] reported the use of a 30 minute sonication period for $5 \mathrm{~g}$ soil samples using $10 \mathrm{~mL}$ acetonitrile, prior to HPLC analysis. In their work, the authors spiked blank soils with explosives prior to their extraction and analysis. Although this sonication time is significantly shorter than that recommended in the EPA methods, it is unlikely that explosives which have been spiked onto a blank soil and extracted days or weeks later will be as tightly-bound to soils which have been contaminated in the field and are being extracted months or years later.

In the present work, the conditions of DeTata [12] were adapted. Firstly, the efficiency of the planned recovery method was assessed to confirm that the short extraction time was sufficient to recover the majority of spiked explosives from the 3 soils used in this work.

The results from these extraction efficiency experiments are displayed in Figure 1.

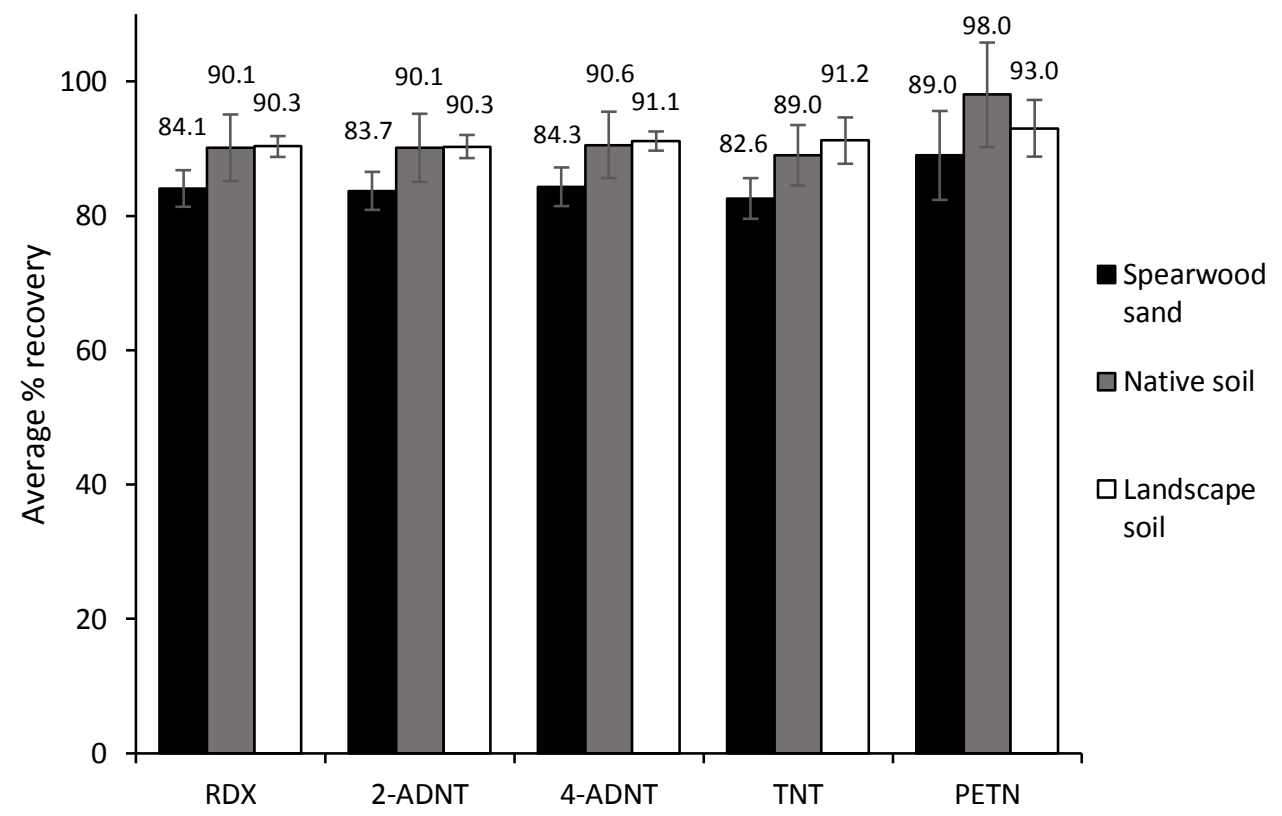

Figure 1: Average recoveries of explosives from the three different soils examined in this work. Error bars show the standard deviations within a set of 7 soil samples.

This extraction efficiency was performed using all three soil types. 2-ADNT and 4-ADNT (common TNT degradation products) were included in these extraction efficiency studies as it is likely that they may have formed by the end of the 6 week ageing period.

It can be seen from Figure 1 that high recoveries of each analyte were obtained from each of the three different soils, with low standard deviations within a set of 7 extracted soil samples. This extraction method using $5 \mathrm{~mL}$ acetonitrile during a 30 minute sonication was therefore used for all subsequent soil extractions. Figure 1 illustrates that slightly lower recoveries of each analyte were obtained from the Spearwood sand, compared to the landscape and native soils. This may be due to inherent chemical and microbiological differences between the different soils (see Table 1), giving rise to different degrees of interaction strength between the explosives and the three soils. 
For these soil extraction validation experiments, soil samples were spiked using an acetonitrile:methanol-based spiking solution, whereas for the actual ageing experiments, soils were spiked with a primarily aqueous (>99.9\% water) spiking solution. Therefore, in order to confirm that the extraction technique would be suitable for the bulk of this study's samples, a set of Spearwood samples was spiked using the aqueous spiking solution (detailed earlier in the experimental section).

Spearwood sand was chosen for this extra soil extraction study as it had given the lowest explosives recoveries from the acetonitrile-based spiked samples (see Figure 1), and thus was deemed the most difficult soil from which to extract the explosives. The results from this aqueous soil extraction validation are displayed in Figure 2.

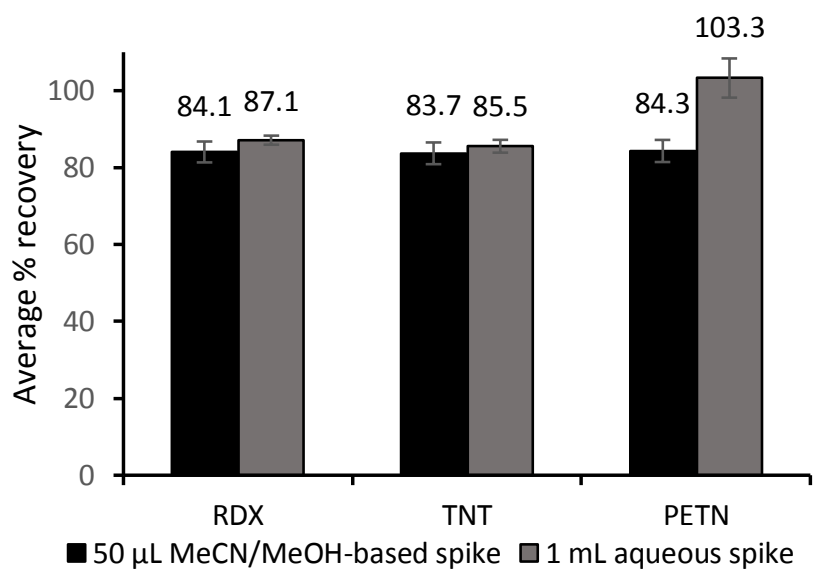

Figure 2: Comparing recoveries of RDX, TNT and PETN from Spearwood soil after acetonitrile:methanol or aqueous soil spiking.

From this, it can be seen that both extraction validations produce similar recoveries of the three explosives from Spearwood sand, with slightly higher recoveries in each case from the aqueous-spiked samples. This confirms that the extraction technique is a suitable method for recovering the explosives from the soils.

In the following section, the pattern of loss of a particular explosive in a particular soil will be presented and discussed for the conditions trialled throughout this work.

\section{Storage at different temperatures}

The results from the 6 week trial examining the effect of alternative soil storage temperatures are detailed in the following sections for each analyte examined.

TNT

Figure 3 displays TNT recoveries from landscape, native and Spearwood samples stored at room temperature, refrigerated and frozen. 

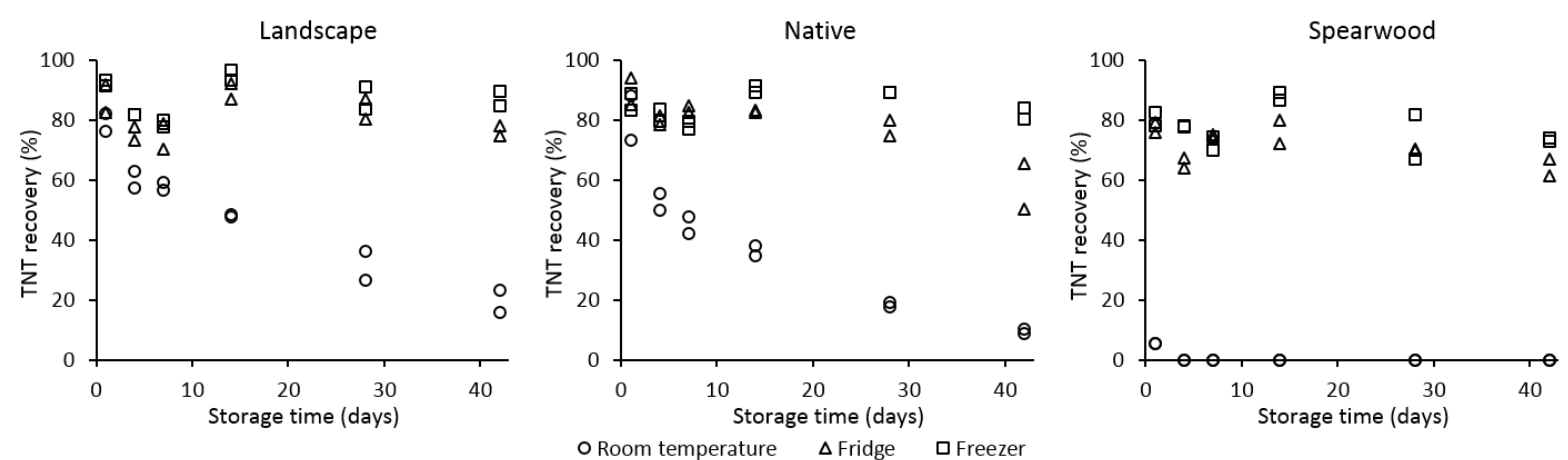

Figure 3: TNT recoveries from spiked landscape, native and Spearwood samples, stored at room temperature, refrigerated and frozen and extracted over 42 days.

Figure 3 shows that storing samples containing TNT at low temperatures, particularly in a freezer, significantly inhibits the loss of TNT after 6 weeks, compared to storage at room temperature. Storage at decreased temperatures is believed to lower the rate of metabolism of any contained bacteria, thus slowing the rate of reduction of TNT's nitro groups. It should be noted that for these 'aged' sample sets, the first extraction and analysis time point was 1 day after spiking. For this reason, no recovery values are plotted for day 0 . It is likely that the day 0 recovery values would fall in the region of those obtained from the 'Soil extraction study', presented in Figures 1 and 2.

By comparing the room temperature results from the 3 soils, it can be seen that there was a very rapid loss of TNT from the Spearwood samples, with almost complete loss after just one day, whereas the decrease in TNT recoveries proceeded more slowly in the landscape and native soils, with TNT recovery possible after 6 weeks. It is highly likely that these observed differences in the rate of TNT loss are due to differences in the rate of microbial degradation and transformation of TNT in the different soils. This can be seen by comparing the levels of 4-ADNT, primarily a microbial TNT degradation product, recovered from the different soils over 6 weeks (see Figure 4). 4-ADNT is presented, rather 2-ADNT, as 4-ADNT is the major reduction product of TNT, and 2-ADNT the minor reduction product $[14,37,38]$. In the current work, 4-ADNT levels were consistently higher than those of 2-ADNT.

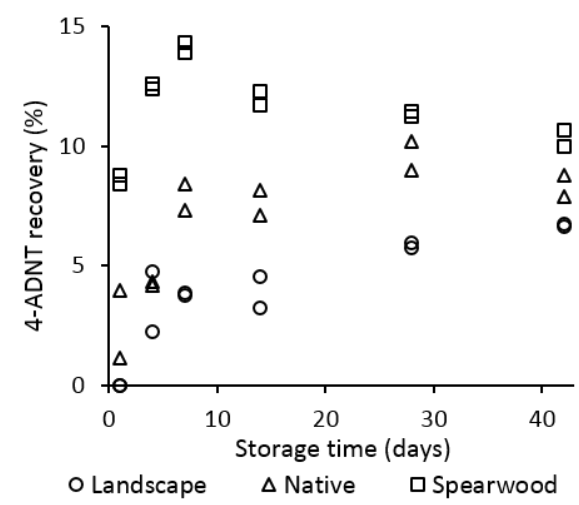

Figure 4: 4-ADNT recoveries from spiked landscape, native and Spearwood samples, stored at room temperature and extracted over 42 days.

Figure 4 indicates that the rate of 4-ADNT formation was lowest in the landscape soil over the 6 weeks, followed by the native soil, with highest recoveries from the Spearwood sand. 
This follows the trend in TNT loss from the three soils. As 4-ADNT is primarily a microbial degradation product of TNT, this lends support to the argument that the majority of the observed TNT loss was due to microbial degradation. However, it is also interesting to note that, by comparing the percentage of TNT recovered over time against the percentage of 4ADNT recovered at the same time point, a discrepancy exists, i.e. the sum is less than $100 \%$. This suggests that another pathway has also been responsible for some of the observed TNT loss over time. This may be explained by alternative attenuation processes or further reduction to the related di- and triaminotoluenes. It is also possible that some of the formed 4ADNT and 2-ADNT had undergone irreversible covalent binding to the humic acids present in the soils [42], to give a reduction in their overall recovery. Much lower 4- and 2-ADNT levels were observed over time from the samples stored in the fridge and freezer, likely due to the low temperatures preventing microbial activity within the soils.

\section{RDX and PETN}

Figure 5 displays RDX (top row) and PETN (bottom row) recoveries from the same set of landscape, native and Spearwood samples.
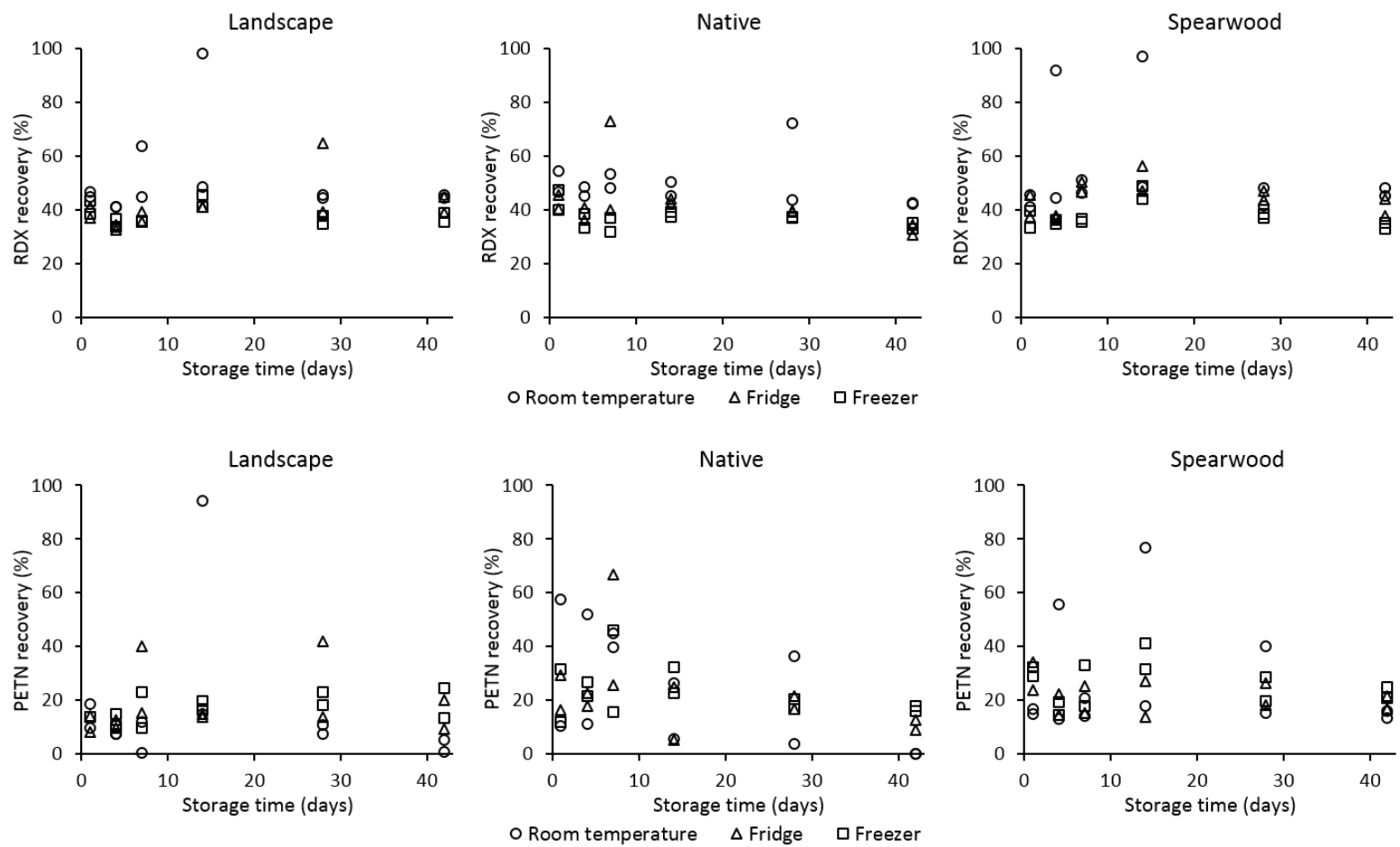

Figure 5: RDX (top row) and PETN (bottom row) recoveries from spiked landscape, native and Spearwood samples, stored at room temperature, refrigerated and frozen and extracted over 42 days.

From Figure 5 it can be seen that the RDX recoveries remained fairly consistent over time from all of the respective soil samples, with little variation across the range of storage temperatures. However, in all samples, even after 1 day, the RDX recovery is only approximately half of the initial quantity spiked into the soils. As demonstrated by the soil extraction study detailed earlier (see Figure 1), almost quantitative RDX recoveries were obtained. This suggests that some initial adsorption or transformation has occurred during the first day of sample storage. Previous authors have proposed interactions between RDX (and its homologue, HMX) and minerals present within the clay fraction of soil. These include 
RDX participating in hydrogen bonding between its nitro groups and surface hydroxyl groups in soil [15, 19], as well as van der Waals interactions [19]. These interactions may therefore have contributed towards the observed reduction in RDX recoveries. It can also be seen from Figure 5 that some fluctuations are present in the recoveries of RDX and PETN from the respective soil samples, in particular those stored at room temperature. The complex composition of soil means that the individual soil samples used may have had some variations between them, which may have contributed to the observed fluctuations in Figure 5.

With regards to PETN recoveries, it can be seen from Figure 5 that the PETN recoveries from each soil show broadly the same trends as each other, with PETN levels remaining relatively low and stable over time. As was the case for RDX, low initial PETN recoveries can be seen from each of the samples. It is possible that this may be due to adsorption processes, such as hydrogen bonding of the PETN to soil components, in a similar manner to that proposed between RDX and the soils. As each molecule of PETN has an extra $\mathrm{NO}_{2}$ group compared to RDX, this may increase the extent of adsorption occurring between PETN and the soils.

Overall, low temperatures have been shown to mitigate TNT degradation, decreasing the rate of formation of the microbial degradation product 4-ADNT. Temperature effects appeared to have a greater influence on TNT recoveries from the soils, compared to RDX and PETN.

\section{Storage under a nitrogen headspace}

Nitrogen purging soil samples prior to storage aimed to limit the aerobic microbial activity in the stored soil samples, though anaerobic degradation would still be possible. This work therefore offers a means of determining the degree of anaerobic degradation of explosives compared to their aerobic degradation.

\section{TNT}

Figure 6 shows the TNT recoveries (top row) from spiked, nitrogen-purged landscape, native and Spearwood soils, in addition to the 4-ADNT recoveries (bottom row) from the respective samples. The results are compared to the previously-discussed room temperature samples under air, with no nitrogen purging. 

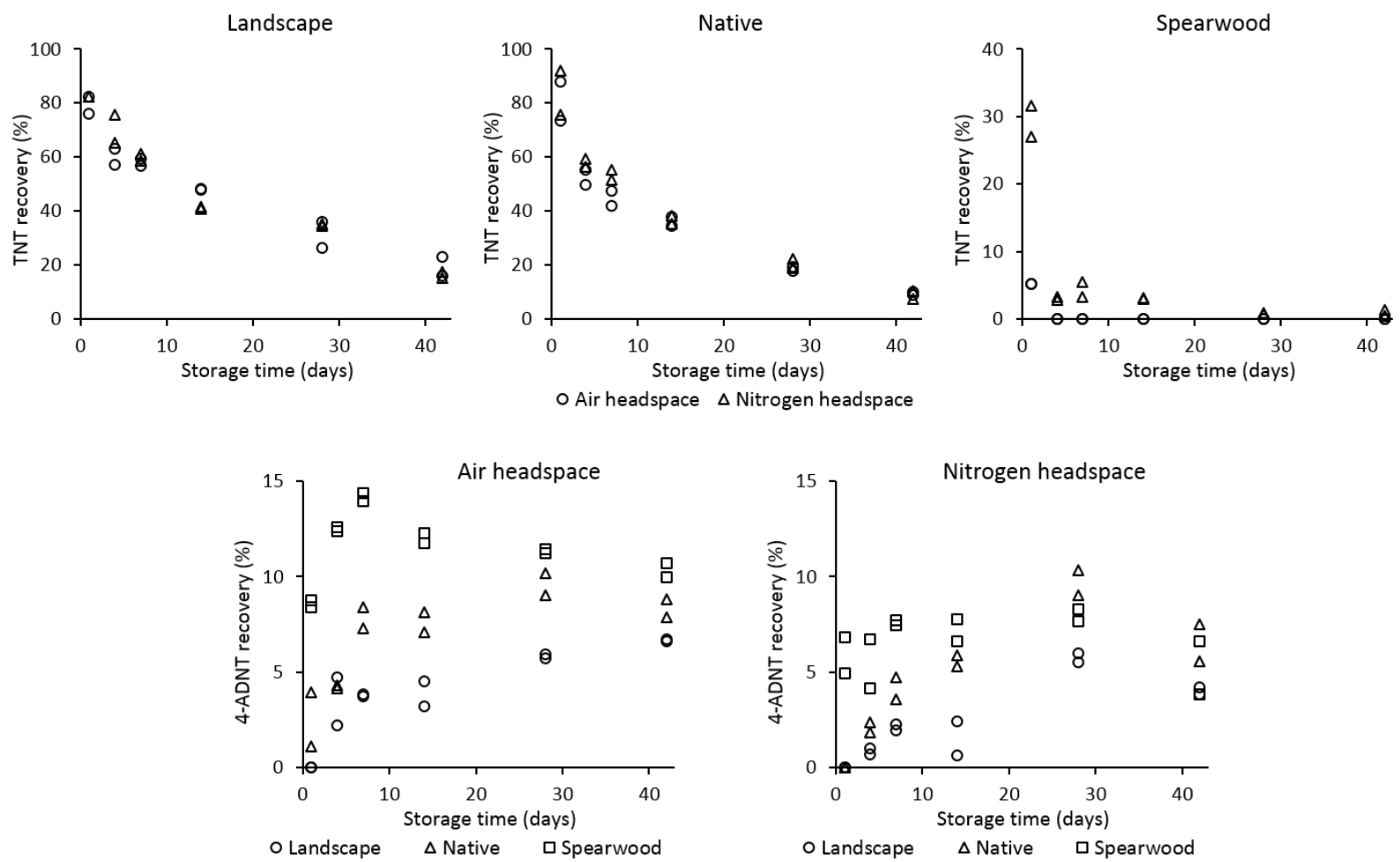

Figure 6: TNT recoveries (top row) and 4-ADNT recoveries (bottom row) from spiked then nitrogen-purged landscape, native and Spearwood samples, stored at room temperature and extracted over 42 days. Note the different y-axis scale for the Spearwood samples to more clearly illustrate recovery differences between the nitrogen-purged vs. air headspace samples.

From Figure 6 it can be seen that storage under nitrogen gave only a minor improvement at best for TNT recoveries, with the level of recovered TNT over time comparable to that from the comparative samples stored under air.

Overall, the slight increase in TNT recoveries from the nitrogen-purged samples suggests that the nitrogen headspace has had some effect on aerobic microbial degradation and transformation processes. However, as the TNT levels still decreased over time from each soil, and 4-ADNT formation was observed over time from the nitrogen-purged samples, anaerobic microbial degradation processes have still occurred.

\section{RDX and PETN}

Figure 7 displays RDX (top row) and PETN (bottom row) recoveries from landscape, native and Spearwood samples after nitrogen purging. The results are compared to the previously- 
discussed room temperature samples under air, with no nitrogen purging.
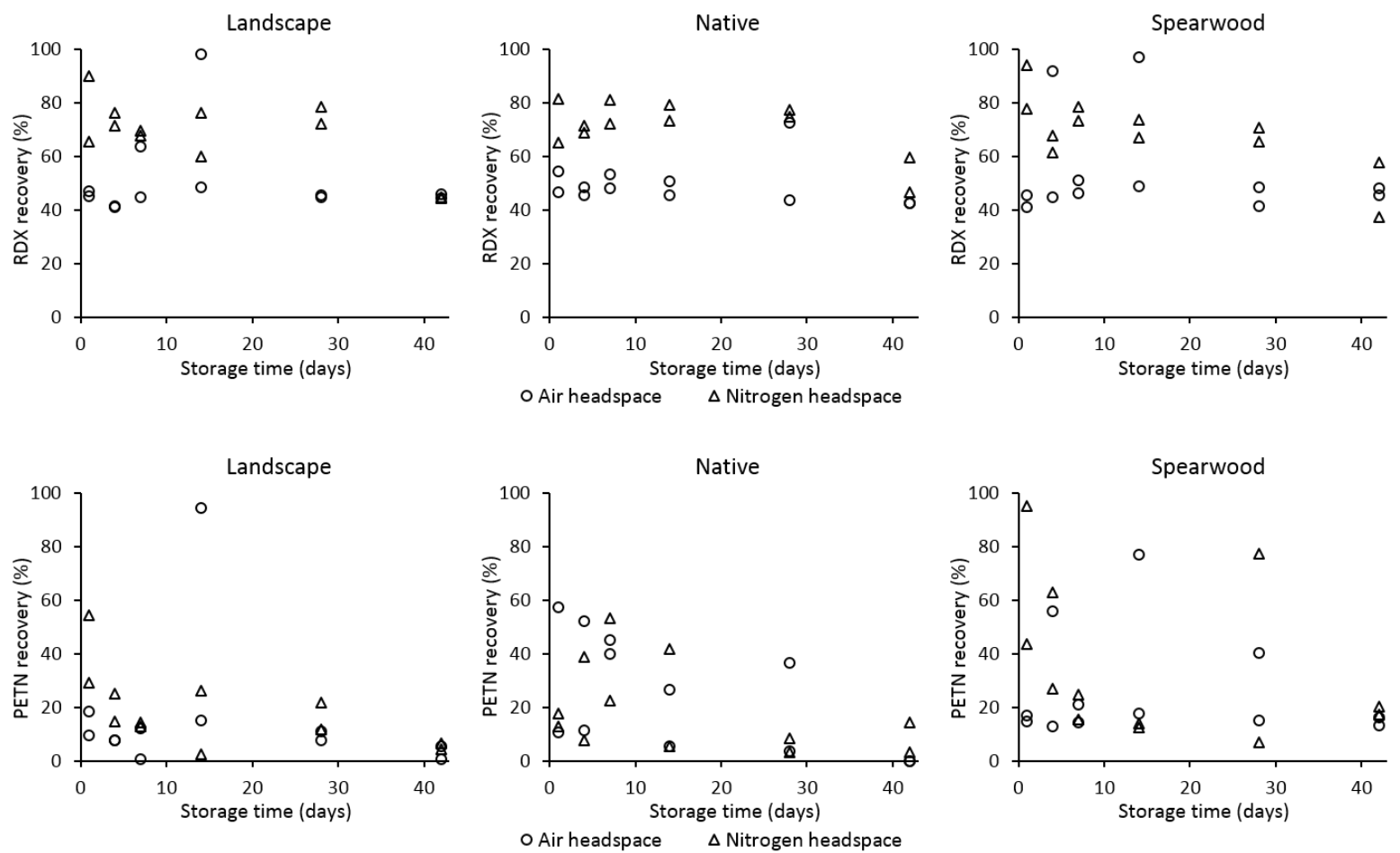

Figure 7: RDX (top row) and PETN (bottom row) recoveries from spiked then nitrogen-purged landscape, native and Spearwood samples, stored at room temperature and extracted over 42 days.

Whereas nitrogen purging appeared to only give a small difference in the recoveries of TNT, it can be seen from Figure 7 that storage under nitrogen appears to have had a much more pronounced effect on RDX recoveries, with significantly higher RDX recoveries across the majority of the time points from the nitrogen-purged samples when compared to the comparative samples stored under air. This suggests that the nitrogen purging is useful in mitigating aerobic RDX degradation. As was the case for Figure 5, it can be seen that some fluctuations are present in the recovered RDX and PETN levels, which may be due to slight variations in the composition of the individual $5 \mathrm{~g}$ soil samples used.

With regards to PETN, it can be seen from Figure 7 that for each condition, the recoveries of PETN are relatively low over time, with the initial day 1 recoveries significantly lower than the recoveries from the soil extraction studies (see Figure 1 and Figure 2). This may be due to an initial adsorption phenomenon occurring between the PETN molecules and soil constituents. As was the case for RDX, higher PETN recoveries can be observed from the nitrogen-purged samples than the samples stored under air, suggesting that a nitrogen headspace may be slowing the rate of anaerobic bacterial degradation.

\section{Storage following gamma irradiation}

Gamma irradiation, and thus sterilisation, of soil samples prior to storage was performed to assess the degradation and transformation of explosives in the absence of any microbial activity. McNamara et al. [48] reviewed the chemical and biological effects of gamma irradiation on soils during the sterilisation process. The authors outline that sterilisation may either cause direct damage to bacterial cell DNA, or bacterial cellular water may undergo 
radiolysis to form $\mathrm{H}, \mathrm{OH}$ and $\mathrm{HO}_{2}$ radicals, promoting indirect breakages in bacterial DNA strands.

TNT

Figure 8 compares the TNT (top row) and 4-ADNT (bottom row) recoveries obtained from the previously-discussed non-irradiated room temperature samples and gamma irradiated landscape, native and Spearwood samples stored at room temperature and extracted over 6 weeks.
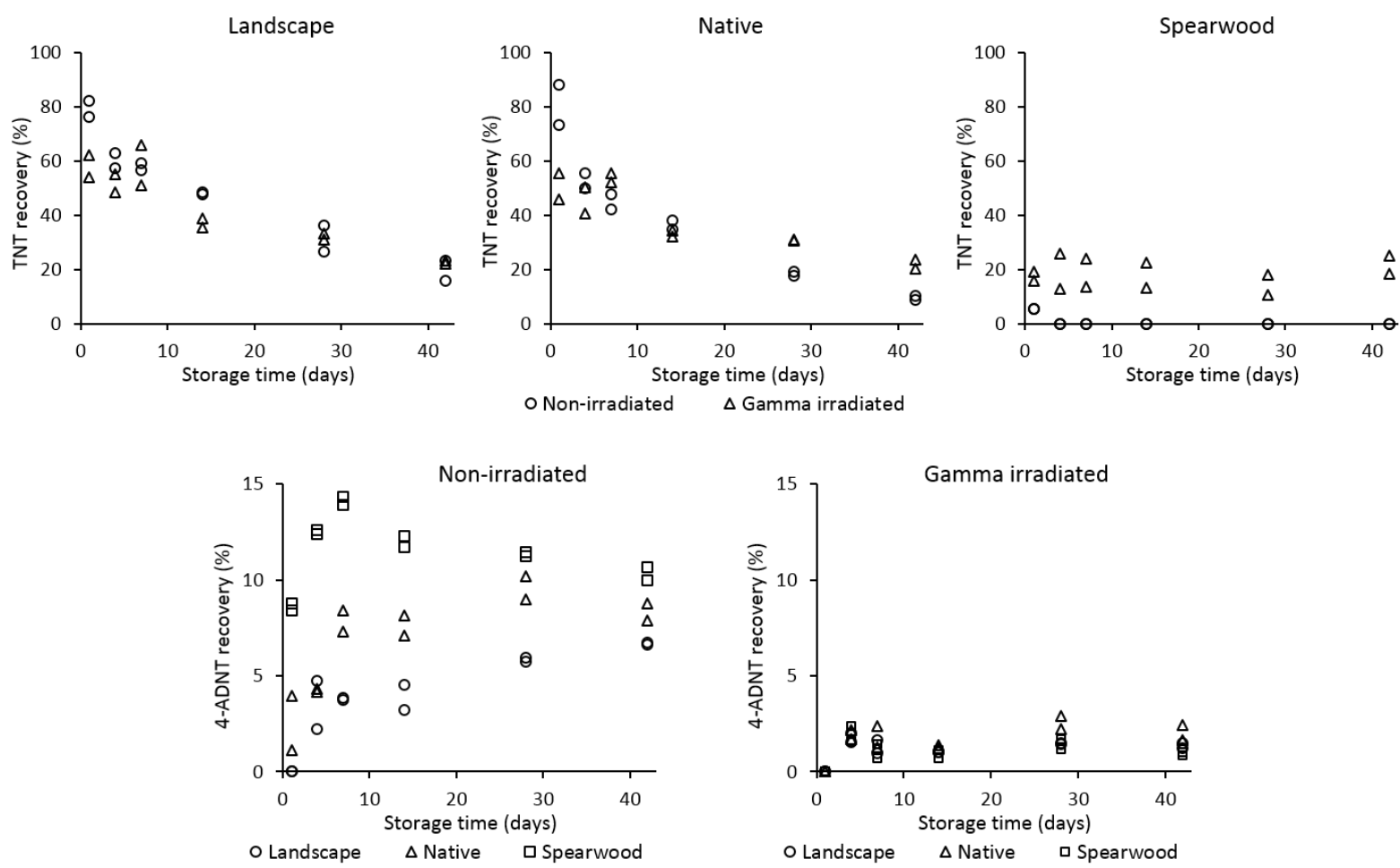

Figure 8: TNT (top row) and 4-ADNT (bottom row) recoveries from spiked then gamma-irradiated landscape, native and Spearwood samples, stored at room temperature and extracted over 42 days.

From Figure 8, similar trends can be observed from the landscape and native soils, with the rate of TNT loss from the gamma irradiated samples slower than from the non-irradiated comparative samples. It is interesting to note that the irradiation process appears to have reduced the Day 1 TNT recoveries from the landscape and native soils, compared to the nonirradiated samples. This suggests that the gamma irradiation process has caused the degradation of a significant proportion of the TNT in the landscape and native soils. In the present work, the soil samples contained $20 \%$ water $w / w$ at the time of irradiation. This water may therefore have undergone radiolysis during the irradiation process to form radical species [48], which may have reacted with the TNT within the samples. Similarly, as the irradiation process is also likely to cause a temperature increase within the samples [48], this may have reduced the required activation energy of the nitroreductase enzymes of any bacteria in the soil, giving a faster rate of TNT transformation and thus a reduction in the day 1 TNT recoveries following the gamma irradiation. 
Although the rate of TNT loss is slowed in the gamma irradiated landscape and native soil samples, there is still a low but detectable drop in TNT levels over time. Ruling out any possible biotic explanation, this may therefore be due to abiotic processes such as adsorption to organic carbon and mineral surfaces in clay.

The Spearwood samples display a very different trend from the landscape and native soils. Interestingly, in the gamma irradiated Spearwood samples, the TNT recoveries over 6 weeks remain stable - in contrast to the TNT recoveries from the irradiated landscape and native samples, where TNT levels slowly decreased over time. If the TNT loss in the gamma irradiated samples was solely a function of the gamma irradiation, then it would be expected that identical proportions of TNT would be lost from each of the soils. However, the widely differing day 1 TNT levels observed following the gamma irradiation suggests that this loss has a dependence on a property inherent to the soil itself; potentially the level of bacteria present in the soil.

The stable TNT recoveries in the Spearwood samples suggest that the main mechanism of TNT loss in the Spearwood samples is due to microbial degradation, with the microbial degradation eliminated due to the gamma irradiation. The large reduction in the Spearwood samples' day 1 TNT recoveries following gamma irradiation is hypothesised to be due to the irradiation process heating the samples and catalysing the bacterial transformation of the TNT. If the Spearwood sand contained higher bacterial populations than the landscape and native soil (as suggested by 4-ADNT recoveries presented earlier), then this would result in a larger proportion of the TNT being transformed, and thus lower initial TNT recoveries, as observed. However, following the completion of the cumulative gamma irradiation process, all of the contained bacteria will have been killed, and it is likely that this has caused the stable TNT levels observed in the irradiated Spearwood sand samples.

Figure 8 also gives a side-by-side comparison of 4-ADNT recoveries over time from nonirradiated vs. gamma irradiated samples. As before, the reported recoveries of 4-ADNT are given as a percentage of the initial quantity of TNT spiked into the soils - i.e. the percentage conversion via reduction of the TNT to 4-ADNT at a given time point.

Significant differences are observed, with the levels of 4-ADNT in the gamma irradiated samples remaining low and relatively constant over time, indicating the irradiation process was successful in killing all of the bacteria in the soils. The low levels of 4-ADNT observed in the three gamma irradiated soils may have formed during the early stages of the 16.3 hour irradiation process, as the applied radiation is cumulative and thus the $70 \mathrm{kGy}$ dose required to ensure the complete eradication of all of the contained bacteria would only have been reached by the very end of the irradiation time, meaning there would have been the opportunity for any bacteria present to begin TNT transformation during the early stages of the irradiation process. In addition, the irradiation process generates heat, which would have helped to catalyse the TNT reduction process to form 4-ADNT. As the levels of 4-ADNT remain stable over time following irradiation, this lends strong support to the notion that 4ADNT formation within the soils can solely be attributed to microbial action, rather than abiotic reduction processes. 


\section{RDX and PETN}

Figure 9 displays the RDX (top row) and PETN (bottom row) recoveries obtained from nonirradiated room temperature samples and gamma irradiated samples extracted over 6 weeks.
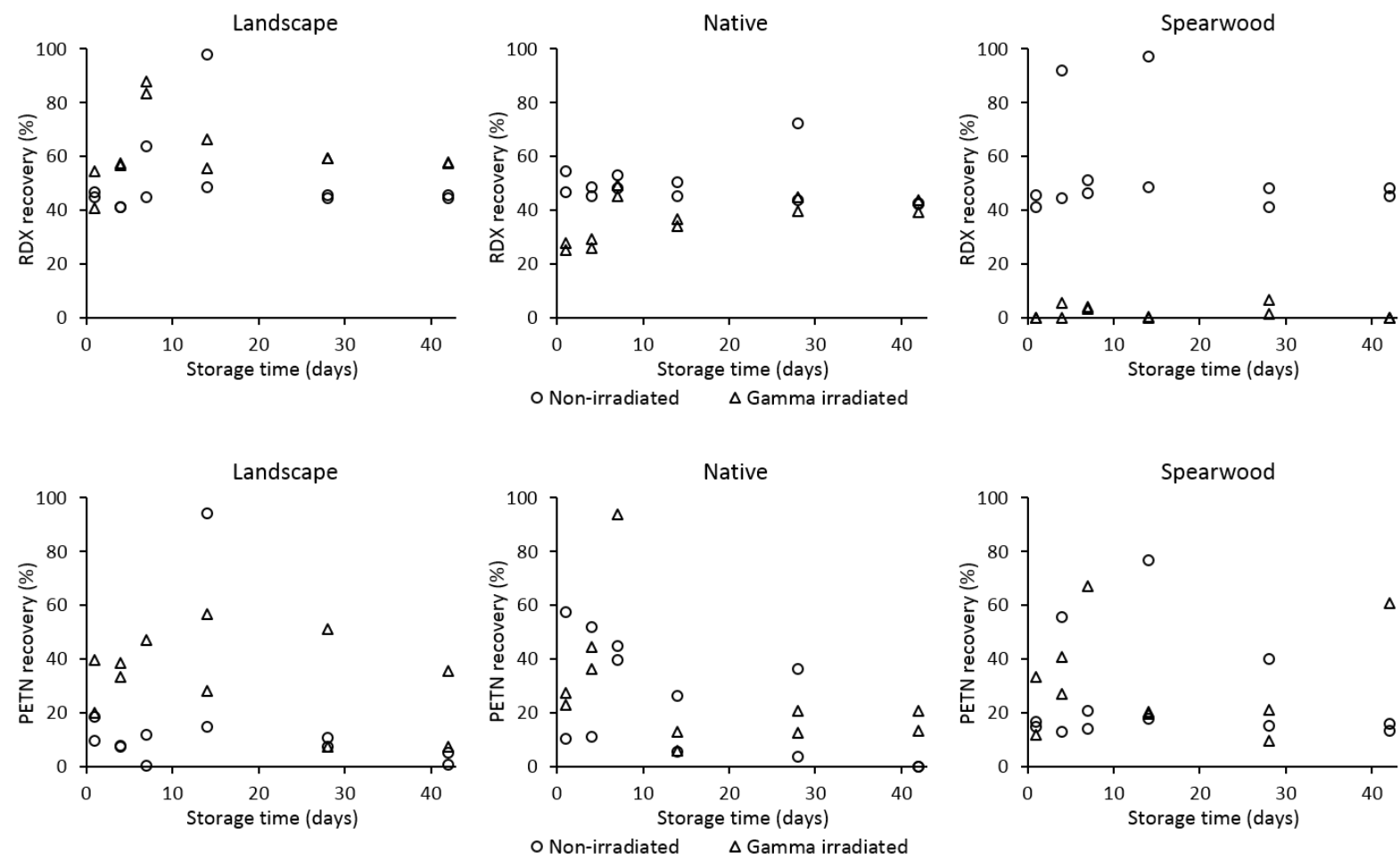

Figure 9: RDX (top row) and PETN (bottom row) recoveries from spiked then gamma-irradiated landscape, native and Spearwood samples, stored at room temperature and extracted over 42 days.

For the landscape soil samples higher RDX recoveries were obtained from the gamma irradiated samples at each time point compared to the non-irradiated samples. In contrast, for the native soil samples, the opposite trend is observed, with the gamma irradiation process appearing to have had a more detrimental effect on RDX present within the native soil samples, compared to the landscape soil.

Similarly, the gamma irradiation process had a significant effect on RDX recoveries from the Spearwood samples. This phenomenon was also observed for the TNT recoveries from this soil, supporting the view that a property of the soil is responsible for this discrepancy. Intriguingly, the RDX recoveries from the gamma irradiated Spearwood samples have become almost negligible at each sampling time point. It is hypothesised that the low RDX recoveries from the irradiated Spearwood samples can be attributed to higher levels of bacteria within the soil compared to the landscape and native soils.

With regards to the PETN recoveries shown in Figure 9, the gamma irradiated samples broadly show stable PETN recoveries, with the gamma-irradiated samples generally giving no clear advantage or disadvantage for PETN recoveries over the non-irradiated comparative samples. As mentioned previously, it is possible that the slight fluctuations in the recoveries of RDX and PETN may be due to slight variations in the composition of the individual soil samples used throughout this work. 
From the results presented here, it is clear that gamma-irradiating samples can have a severely detrimental effect on any explosives contained within a sample. This is the first known piece of work where soils have been sterilised after spiking with explosives, and the results have clearly shown that although in the case of samples containing TNT, gamma irradiation can prevent the formation of microbial degradation products, it can give detrimental results for samples containing RDX, meaning it is not a viable technique with which to stabilise explosives present in soil samples as the nature of explosives present in a soil sample is likely to be unknown prior to extraction.

It is clear from Figure 9 that gamma irradiating different types of soil samples may cause very large differences in the stability of a given explosive, and this appears to be both soiland explosive-dependent. In a real-world scenario the soil type would not be known, nor would the type of explosive(s) present, so the gamma irradiation of casework samples is not recommended.

In all of the gamma-irradiated samples, a number of extra peaks were observed in all of the LC chromatograms, not observed in any of the non-irradiated or nitrogen-purged samples. These peaks suggest the gamma irradiation process promotes a different explosives transformation pathway compared to that of the non-irradiated and nitrogen-purged samples. These extra peaks occurred across all of the three soils used during the gamma irradiation studies. Example chromatograms containing these extra peaks are provided in the Supporting Information, Figure S-3 to Figure S-9. It is possible that the analytes corresponding to these peaks could be identified using a mass-spectral based technique such as LC-MS.

To investigate whether it is solely the high temperatures of the gamma irradiation (in conjunction with the respective bacterial loadings of the soils) responsible for the observed large losses of TNT and RDX following gamma irradiation, or whether this observed decrease also has a dependence on any radical ions formed during the gamma irradiation process, one possible method of exploring this would be to prepare a further set of samples and store them at elevated temperatures (in the short term) to mimic the initial temperature increase occurring during the gamma irradiation process. The samples could then be stored at room temperature for 6 weeks, analogous to the samples presented here. If temperature (in combination with bacteria present in the soils) were the main cause of the losses, then the results should mirror those displayed here for gamma irradiation. However, if the presence of radicals were also necessary to bring about such a dramatic decrease in the levels of TNT and RDX, then a difference would likely be observed in the recoveries over time.

\section{Conclusions}

This work has shown that different explosives may have different degradation and transformation pathways in soils, and the fate of explosives in soil also has a strong dependence on the nature of the soil itself. For TNT in particular, in the Spearwood sand, a very rapid rate of degradation was observed at room temperature, and this is taken to be the 'worst-case-scenario' which this work aims to prevent from occurring in the future.

Generally, lower PETN recoveries were observed compared to the recoveries of RDX. This 
may be due to PETN being more susceptible to reduction of its nitro groups compared to RDX.

An enhanced TNT stability was observed over time from soil samples stored at lower temperatures, particularly those stored in the freezer, compared to samples stored at room temperature. Nitrogen purging of explosives-spiked soil samples in some cases enhanced stability of the explosives assessed in this work. Results relating to the use of gamma irradiation were dependent upon the type of soil used, in addition to the type of explosive. For example, a very large attenuation of the initial TNT and RDX levels was observed in the gamma irradiated Spearwood sand samples, compared to the landscape and native soils.

It is acknowledged that in the present work, soils were spiked using solutions of explosives, which may not perfectly represent explosives loading to soils using an actual detonation process. Studies are therefore currently underway to compare our solution-spiked explosives recoveries with those from the same soil types spiked using actual detonations.

Future steps for this work would be to repeat the same set of experiments using a wider range of explosives and soils. It would also be of interest to trial gamma irradiating some dry, spiked soil samples, to see whether an enhanced stability of the explosives was obtained. Freeze-drying spiked soils and then assessing explosives recoveries would also be an interesting piece of future research. In addition, studies are currently underway to determine why the fastest rate of TNT degradation occurred in the Spearwood sand samples.

\section{Acknowledgements}

The explosives standards and consumables used throughout this work were kindly provided by the Forensic Science Laboratory, ChemCentre, WA. Many thanks are due to Jeremy Brown from ChemCentre for his help with preparing the soils used in this work. HAY is supported by a Curtin International Postgraduate Research Scholarship.

\section{References}

[1] J. Pichtel, Distribution and fate of military explosives and propellants in soil: a review, Appl. Environ. Soil Sci., (2012) 617236, 617233 pp.

[2] M.E. Walsh, A.D. Hewitt, T.F. Jenkins, C.A. Ramsey, M.R. Walsh, S.R. Bigl, C.M.

Collins, M.A. Chappell, Assessing sample processing and sampling uncertainty for energetic residues on military training ranges: method 8330B, ACS Symp. Ser., 1069 (2011) 91-106.

[3] A. Halasz, C. Groom, E. Zhou, L. Paquet, C. Beaulieu, S. Deschamps, A. Corriveau, S. Thiboutot, G. Ampleman, C. Dubois, J. Hawari, Detection of explosives and their degradation products in soil environments, J. Chromatogr. A, 963 (2002) 411-418.

[4] M.E. Walsh, Determination of nitroaromatic, nitramine, and nitrate ester explosives in soil by gas chromatography and an electron capture detector, Talanta, 54 (2001) 427-438. [5] J.C. Oxley, J.L. Smith, E. Resende, E. Pearce, Quantification and aging of the post-blast residue of TNT landmines, J. Forensic Sci., 48 (2003) 742-753.

[6] M.E. Walsh, T.F. Jenkins, Identification of TNT transformation products in soil, Cold Regions Res. Eng. Lab., 1992, pp. 37 pp.

[7] M.R. Walsh, M.E. Walsh, K. Gagnon, A.D. Hewitt, T.F. Jenkins, Subsampling of Soils Containing Energetics Residues, Soil Sediment Contam., 23 (2014) 452-463. 
[8] S. Sagi-Ben Moshe, Z. Ronen, O. Dahan, N. Weisbrod, L. Groisman, E. Adar, R. Nativ, Sequential biodegradation of TNT, RDX and HMX in a mixture, Environ. Pollut. (Oxford, U. K.), 157 (2009) 2231-2238.

[9] N. Singh, D. Hennecke, J. Hoerner, W. Koerdel, A. Schaeffer, Degradation of

trinitrotoluene in contaminated soils as affected by its initial concentrations and its binding to soil organic matter fractions, J. Environ. Sci. Health, Part A: Toxic/Hazard. Subst. Environ. Eng., 43 (2008) 348-356.

[10] G.K. Vasilyeva, V.D. Kreslavski, B.-T. Oh, P.J. Shea, Potential of activated carbon to decrease 2,4,6-trinitrotoluene toxicity and accelerate soil decontamination, Environ. Toxicol. Chem., 20 (2001) 965-971.

[11] C.L. Kitts, D.P. Cunningham, P.J. Unkefer, Isolation of three hexahydro-1,3,5-trinitro1,3,5-triazine-degrading species of the family Enterobacteriaceae from nitramine explosivecontaminated soil, Appl. Environ. Microbiol., 60 (1994) 4608-4611.

[12] D. DeTata, P. Collins, A. McKinley, An investigation into the fate of organic explosives in soil, Aust. J. Forensic Sci., 45 (2012) 71-84.

[13] S. Sagi-Ben Moshe, O. Dahan, N. Weisbrod, A. Bernstein, E. Adar, Z. Ronen, Biodegradation of explosives mixture in soil under different water-content conditions, J. Hazard. Mater., 203-204 (2012) 333-340.

[14] H. Yamamoto, M.C. Morley, G.E. Speitel, Jr., J. Clausen, Fate and transport of high explosives in a sandy soil: adsorption and desorption, Soil Sediment Contam., 13 (2004) 459477.

[15] F. Monteil-Rivera, C. Groom, J. Hawari, Sorption and Degradation of Octahydro1,3,5,7-tetranitro-1,3,5,7-tetrazocine in Soil, Environ. Sci. Technol., 37 (2003) 3878-3884.

[16] T.W. Sheremata, A. Halasz, L. Paquet, S. Thiboutot, G. Ampleman, J. Hawari, The Fate of the Cyclic Nitramine Explosive RDX in Natural Soil, Environ. Sci. Technol., 35 (2001) 1037-1040.

[17] C.K. Bayne, D.D. Schmoyer, R.A. Jenkins, Practical Reporting Times for Environmental Samples, Environ. Sci. Technol., 28 (1994) 1430-1436.

[18] M.P. Maskarinec, C.K. Bayne, L.H. Johnson, S.K. Holladay, R.A. Jenkins, B.A.

Tomkins, Stability of explosives in environmental water and soil samples, Oak Ridge Natl. Lab., 1991, pp. 88 pp.

[19] C.C. Ainsworth, S.D. Harvey, J.E. Szecsody, M.A. Simmons, V. Cullinan, Relationship between the leachability characteristics of unique energetic compounds and soil properties, Battelle Memorial Inst., 1993, pp. 137 pp.

[20] H.T. Mayfield, E. Burr, M. Cantrell, Analysis of explosives in soil using solid phase microextraction and gas chromatography, Anal. Lett., 39 (2006) 1463-1474.

[21] C.A. Groom, S. Beaudet, A. Halasz, L. Paquet, J. Hawari, Detection of the cyclic nitramine explosives hexahydro-1,3,5-trinitro-1,3,5-triazine (RDX) and octahydro-1,3,5,7tetranitro-1,3,5,7-tetrazine (HMX) and their degradation products in soil environments, $\mathrm{J}$. Chromatogr. A, 909 (2001) 53-60.

[22] C.L. Grant, T.F. Jenkins, K.F. Myers, E.F. McCormick, Holding-time estimates for soils containing explosives residues: comparison of fortification vs. field contamination, Environ. Toxicol. Chem., 14 (1995) 1865-1874.

[23] A.M. Jaramillo, T.A. Douglas, M.E. Walsh, T.P. Trainor, Dissolution and sorption of hexahydro-1,3,5-trinitro-1,3,5-triazine (RDX) and 2,4,6-trinitrotoluene (TNT) residues from detonated mineral surfaces, Chemosphere, 84 (2011) 1058-1065.

[24] T.A. Douglas, M.E. Walsh, C.J. McGrath, C.A. Weiss, A.M. Jaramillo, T.P. Trainor, Desorption of nitramine and nitroaromatic explosive residues from soils detonated under controlled conditions, Environ. Toxicol. Chem., 30 (2010) 345-353. 
[25] T.A. Douglas, M.E. Walsh, C.J. McGrath, C.A. Weiss, Jr., Investigating the fate of nitroaromatic (TNT) and nitramine (RDX and HMX) explosives in fractured and pristine soils, J. Environ. Qual., 38 (2009) 2285-2294.

[26] K.M. Dontsova, C. Hayes, J.C. Pennington, B. Porter, Sorption of high explosives to water-dispersible clay: influence of organic carbon, aluminosilicate clay, and extractable iron, J. Environ. Qual., 38 (2009) 1458-1465.

[27] R. Batlle, C. Nerin, C. Crescenzi, H. Carlsson, Supercritical Fluid Extraction of Energetic Nitroaromatic Compounds and Their Degradation Products in Soil Samples, Anal. Chem., 77 (2005) 4241-4247.

[28] S.L. Larson, W.A. Martin, B.L. Escalon, M. Thompson, Dissolution, Sorption, and Kinetics Involved in Systems Containing Explosives, Water, and Soil, Environ. Sci. Technol., 42 (2008) 786-792.

[29] S.B. Haderlein, K.W. Weissmahr, R.P. Schwarzenbach, Specific Adsorption of Nitroaromatic Explosives and Pesticides to Clay Minerals, Environ. Sci. Technol., 30 (1996) 612-622.

[30] G. Alavi, M. Chung, J. Lichwa, M. D'Alessio, C. Ray, The fate and transport of RDX, HMX, TNT and DNT in the volcanic soils of Hawaii: A laboratory and modeling study, J. Hazard. Mater., 185 (2011) 1600-1604.

[31] T.A. Douglas, M.E. Walsh, C.A. Weiss, Jr., C.J. McGrath, T.P. Trainor, Desorption and Transformation of Nitroaromatic (TNT) and Nitramine (RDX and HMX) Explosive Residues on Detonated Pure Mineral Phases, Water, Air, Soil Pollut., 223 (2012) 2189-2200.

[32] I. Jayamani, M.P. Manzella, A.M. Cupples, RDX Degradation Potential in Soils Previously Unexposed to RDX and the Identification of RDX-Degrading Species in One Agricultural Soil Using Stable Isotope Probing, Water, Air, Soil Pollut., 224 (2013) 1-15. [33] D. Royds, S.W. Lewis, A.M. Taylor, A case study in forensic chemistry: The Bali bombings, Talanta, 67 (2005) 262-268.

[34] L. Ma, B. Xin, Y. Chen, Direct mass spectrometric detection of trace explosives in soil samples, Analyst (Cambridge, U. K.), 137 (2012) 1730-1736.

[35] A. Choodum, P. Kanatharana, W. Wongniramaikul, N. Nic Daeid, Using the iPhone as a device for a rapid quantitative analysis of trinitrotoluene in soil, Talanta, 115 (2013) 143-149. [36] L. Capka, Z. Vecera, P. Mikuska, J. Sestak, V. Kahle, A. Bumbova, A portable device for fast analysis of explosives in the environment, J. Chromatogr. A, 1388 (2015) 167-173. [37] D. Kalderis, A.L. Juhasz, R. Boopathy, S. Comfort, Soils contaminated with explosives: environmental fate and evaluation of state-of-the-art remediation processes (IUPAC technical report), Pure Appl. Chem., 83 (2011) 1407-1484.

[38] A. Esteve-Nunez, A. Caballero, J.L. Ramos, Biological degradation of 2,4,6-

trinitrotoluene, Microbiol. Mol. Biol. Rev., 65 (2001) 335-352.

[39] M.A. Chappell, Solid-phase considerations for the environmental fate of TNT and RDX in soil, ACS Symp. Ser., 1069 (2011) 1-25, 22 plates.

[40] O. Drzyzga, D. Bruns-Nagel, T. Gorontzy, K.-H. Blotevogel, E. Von Low, Anaerobic incorporation of the radiolabeled explosive TNT and metabolites into the organic soil matrix of contaminated soil after different treatment procedures, Chemosphere, 38 (1999) 20812095.

[41] J. Eriksson, S. Frankki, A. Shchukarev, U. Skyllberg, Binding of 2,4,6-Trinitrotoluene, Aniline, and Nitrobenzene to Dissolved and Particulate Soil Organic Matter, Environ. Sci. Technol., 38 (2004) 3074-3080.

[42] K.A. Thorn, K.R. Kennedy, 15N NMR Investigation of the Covalent Binding of Reduced TNT Amines to Soil Humic Acid, Model Compounds, and Lignocellulose, Environ. Sci. Technol., 36 (2002) 3787-3796. 
[43] A.Z. Li, K.A. Marx, J. Walker, D.L. Kaplan, Trinitrotoluene and Metabolites Binding to Humic Acid, Environ. Sci. Technol., 31 (1997) 584-589.

[44] J.C. Pennington, J.M. Brannon, Environmental fate of explosives, Thermochim. Acta, 384 (2002) 163-172.

[45] EPA, Method 8330B, Test methods - SW-846US EPA, 2006, pp. 1-31, Appendix 3129.

[46] EPA, Method 8330A, Test methods - SW-846US EPA, 2007, pp. 1-28.

[47] M.E. Walsh, C.A. Ramsey, T.F. Jenkins, The effect of particle size reduction by grinding on subsampling variance for explosives residues in soil, Chemosphere, 49 (2002) 1267-1273.

[48] N.P. McNamara, H.I.J. Black, N.A. Beresford, N.R. Parekh, Effects of acute gamma irradiation on chemical, physical and biological properties of soils, Applied Soil Ecology, 24 (2003) 117-132. 